\title{
Perforated jejunal diverticulitis with extensive diverticulosis: A case report
}

\author{
Zied Hadrich $^{1,2}$ (1) | Hazem Ben Ameur ${ }^{1,2}$ | Abderrahmen Masmoudi, | \\ Amine Zouari $^{1,2}$ | Salah Boujelben ${ }^{1,2}$ | Rafik Mzali,2
}

${ }^{1}$ Departement of General Surgery, Habib Bourguiba Hospital, Sfax, Tunisia

${ }^{2}$ Faculty of Medicine of Sfax, University of Sfax, Sfax, Tunisia

Correspondence

Zied Hadrich, Department of General

Surgery, Habib Bourguiba Hospital,

Sfax, Tunisia.

Email: hadrich1988@gmail.com

Funding information

None

\begin{abstract}
Jejunal diverticulitis is a rare condition that almost occurs in the elderly. An extensive diverticulosis associated is exceptional and can make the treatment more challenging.
\end{abstract}

K E Y W O R D S

diverticulitis, jejunum, surgery

\section{1 | INTRODUCTION}

Diverticular disease was first described by Soemmerring in 1794 and later by Astley Cooper in 1809. In 1906, Gordinier and Shil performed the first operation for diverticulum. ${ }^{1}$ Jejunal diverticula are rarely revealed by complications such as perforation, diverticulitis, hemorrhage, or obstruction (less than a third of cases)., ${ }^{2,3}$

We report a case of perforated jejunal diverticulitis. We propose to describe diagnostic and therapeutic modalities.

\section{2 | CASE PRESENTATION}

A 74-year-old man with history of diabetes mellitus presented to the emergency department with a severe epigastric pain and vomiting for $24 \mathrm{~h}$. On examination, there was tenderness in epigastric region. Laboratory tests revealed elevated leukocytes $\left(16,300 / \mathrm{mm}^{3}\right)$ and normal level of lipase.

CT scan showed multiple jejunal diverticula. One of the diverticula had a thickened enhancing wall with a surrounding significant inflammatory reaction and extraluminal gas bubbles suggestive of perforation. There was no abscess formation nor fluid collection (Figure 1).

An urgent surgery was performed. During laparotomy, multiple large jejunal diverticula were found (Figure 2A). One of diverticula was frankly inflammatory with false membranes (Figure 2B: blue arrow) without obvious perforation, free fluid, or abscess. A $50 \mathrm{~cm}$ intestinal resection removing this diverticulum was performed followed by a side-to-side mechanical anastomosis.

The postoperative course was uneventful, and the patient was discharged on the $7^{\text {th }}$ postoperative day.

The patient did not present any recurrence of pain at 12 months of follow-up.

\section{3 | DISCUSSION}

Acquired small-bowel diverticulum is a herniation of the mucosa and submucosa through the muscularis propria at the penetration points of the vasa recta, which are points of vulnerability in the intestinal wall. It is a rare condition 


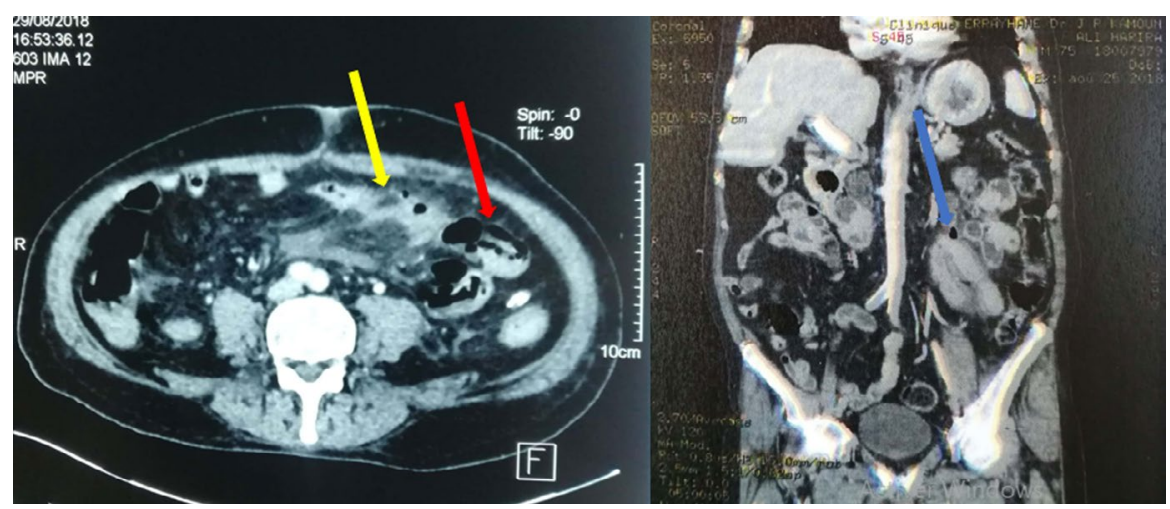

F I G URE 1 CT scan showing diffuse jejunal diverticula (red arrow), thickened enhancing wall with a surrounding significant inflammatory reaction (yellow arrow) and extraluminal gas (blue arrow)

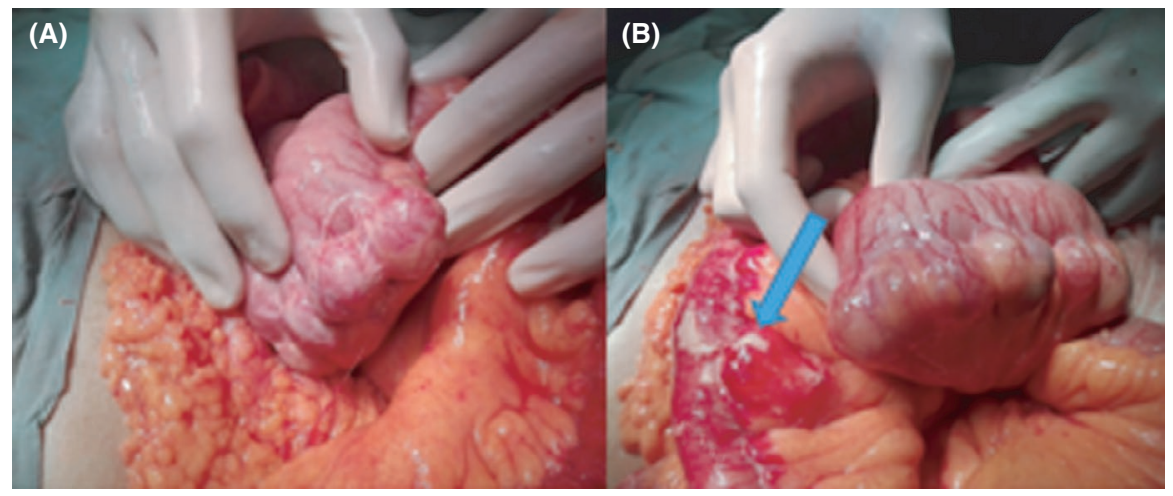

F I G URE 2 Intraoperative findings.

(A) multiple jejunal diverticula. (B) Intraoperative findings: diverticula frankly inflammatory with false membranes (blue arrow) without obvious perforation, free fluid, or abscess

$(1 \%-4.6 \%)$ and usually occurs between the ages of 60 and $70 .^{3}$

Diverticulitis is the most common complication. In the literature, two factors were incriminated in its genesis: first, the stasis of the jejunum contents in the diverticulum and second the mucosal edema causing obstruction of the diverticular neck. ${ }^{3-5}$ However, the diverticulitis is much less common in the jejunum than in colonic diverticula probably because of diverticulum larger size, better intraluminal flow, and lower concentration of bacteria. ${ }^{3}$

The perforation of jejunal diverticulum is rare $(2.1 \%$ to $7 \%$ of diverticulitis), probably because of intestinal intraluminal low pressures. ${ }^{3,6}$ An extensive diverticulum as it was the case of our patient may increase the probability of complications. ${ }^{6}$

Uncomplicated diverticulitis may be asymptomatic or mimic the symptoms of irritable bowel syndrome: paroxysmal abdominal pain with cramping, a feeling of distension after eating, and diarrhea. ${ }^{6}$ In diverticulitis, the symptoms are similar to those of acute peritonitis secondary to perforated duodenal ulcer or acute pancreatitis. In our patient, the clinical manifestations mimicked acute pancreatitis but lipase was normal.

On CT scan, jejunal diverticula are shown as round structures outside of the small-bowel lumen and containing some combination of contrast material, air, and debris. The large jejunal diverticula (massive diverticulosis) like our patient can be distinguished from adjacent small-bowel loops by their different contents and by the absence of conniving valvulae. ${ }^{7}$ Frequent findings seen in diverticulitis are an inflammatory mass which may contain gas, wall thickening of an involved segment, edema of the surrounding tissues, and fluid collection. ${ }^{1,5}$

Nonperforated jejunal diverticulitis is managed conservatively with antibiotics, intravenous fluids, and bowel rest. ${ }^{8,9}$ For perforated jejunal diverticula, surgery is mandatory. The recommended technique is resection of the involved intestinal segment. ${ }^{3,7,10}$ In case of extensive diverticulosis (like our patient), surgery may expose the patient to short bowel syndrome that is why it should be indicated only in case of generalized peritonitis or after the failure of medical and radiological treatment. The anastomosis can be performed only in the absence of generalized peritonitis and septic shock, and it should be done on intestinal segments without diverticula.

\section{CONCLUSION}

Jejunal diverticulitis represents a rare disease. Diagnosis is based on CT scan. Surgical resection is recommended for perforated cases but the association with jejunal diverticula makes management more challenging.

\section{ACKNOWLEDGEMENTS}

Published with the consent of the patient. 


\section{CONFLICT OF INTEREST}

None declared.

\section{AUTHOR CONTRIBUTIONS}

$\mathrm{Z}$ Hadrich: conceived the idea for the document and contributed to the writing and editing of the manuscript. H Ben Ameur: contributed to the writing and editing of the manuscript. A Masmoudi: reviewed and edited the manuscript. A Zouari: reviewed and edited the manuscript. S Boujelben: contributed to the literature review, manuscript writing, editing, and review of the manuscript. All authors read and approved the final manuscript.

\section{ETHICAL APPROVAL}

Personal data have been respected.

\section{CONSENT}

Published with the consent of the patient.

\section{DATA AVAILABILITY STATEMENT}

Personal data of the patient were respected. No data are available for this submission.

\section{ORCID}

Zied Hadrich (1) https://orcid.org/0000-0002-5048-3755

\section{REFERENCES}

1. Kumar D, Meenakshi M. Complicated jejunal diverticulitis with unusual presentation. Radiol Case Rep. 2018;13:58-64.
2. Serrano-González J, Artés-Caselles M. Román-García de León L, Plá-Sánchez P, Sánchez-Turrión V. Management of jejunal diverticulitis. Experience in our center Cir Cir. 2018;86:148-151.

3. Harbi H, Kardoun N, Fendri S, et al. Jejunal diverticulitis. Review and treatment algorithm. Presse Med. 2017;46:1139-1143.

4. Ng ZQ, Theophilus M, Navadgi S, Menon T, Wijesuriya R. Jejunal diverticulitis: a single-center experience and proposed management algorithm. Surg Infect. 2019;20:499-503.

5. Harris LM, Volpe CM, Doerr RJ. Small bowel obstruction secondary to enterolith impaction complicating jejunal diverticulitis. Am J Gastroenterol. 1997;92:1538-1540.

6. Syllaios A, Koutras A, Zotos PA, et al. Jejunal diverticulitis mimicking small bowel perforation: case report and review of the literature. Chirurgia. 2018;113:576-581.

7. Fintelmann F, Levine MS, Rubesin SE. Jejunal diverticulosis: findings on CT in 28 patients. Am J Roentgenol. 2008;190:1286-1290.

8. Gurala D, Idiculla PS, Patibandla P, Philipose J, Krzyzak M, Mukherjee I. Perforated jejunal diverticulitis. Case Rep Gastroenterol. 2019;13:521-525.

9. Abboud B, Aouad R, Jaoude JB, Ghorra C. A rare cause of acute abdomen: jejunal diverticulitis. Presse Med. 2008;37:416-419.

10. Schloericke E, Zimmermann MS, Hoffmann M, et al. Complicated jejunal diverticulitis: a challenging diagnosis and difficult therapy. Saudi J Gastroenterol. 2012;18:122-128.

How to cite this article: Hadrich Z, Ben Ameur H, Masmoudi A, Zouari A, Boujelben S, Mzali R. Perforated jejunal diverticulitis with extensive diverticulosis: A case report. Clin Case Rep. 2021;9:e04877. https://doi.org/10.1002/ccr3.4877 